\title{
Returning to sport after anterior cruciate ligament reconstruction in amateur sports men: a retrospective study
}

\author{
Angela Notarnicola ${ }^{1,2}$ \\ Giuseppe Maccagnano ${ }^{1}$ \\ Federico Barletta ${ }^{2}$ \\ Leonardo Ascatigno ${ }^{2}$ \\ Leopoldo Astuto ${ }^{2}$ \\ Antonio Panella ${ }^{1}$ \\ Silvio Tafuri 2,3 \\ Biagio Moretti ${ }^{1,2}$ \\ 1 Orthopaedics Unit, Department of Basic Medical \\ Science, Neuroscience and Sensory Organs, \\ University of Bari "Aldo Moro", Bari, Italy \\ 2 Degree Course of Motor and Sport Science, \\ University of Bari "Aldo Moro", Bari, Italy \\ 3 Department of Biomedical Science and Human \\ Oncology, University of Bari "Aldo Moro", Bari, Italy \\ Corresponding author: \\ Angela Notarnicola \\ Orthopaedics Unit, Department of Basic Medical \\ Science, Neuroscience and Sensory Organs, \\ University of Bari "Aldo Moro" \\ Piazza G. Cesare 11 \\ 70124 Bari, Italy \\ E-mail: angelanotarnicola@yahoo.it
}

\section{Summary}

Background: According to the literature, $95 \%$ of professional athletes return to their sport after anterior cruciate ligament (ACL) reconstruction surgery. The main objective of this study was to verify the return to sport after ACL reconstruction in a homogenous group of amateur sportsmen and sportswomen in a series of Italian patients.

Materials and methods: We designed a retrospective study in which we analyzed the amateur sports patients operated for $A C L$ reconstruction. We verified whether they had returned to sporting activities by comparing the pre- and post-operative Tegner activity scores.

We then analyzed the average time to restart the sporting activity and the Lysholm and International Knee Documenting Committee (IKDC) scores.

Results: We analyzed 80 subjects: $47.5 \%$ restarted a sports activity, on average after eight months, with a significant reduction of their competitive level or physical commitment, as expressed by the Tegner activity score (pre-operative: 6.9 ; post-operative: $3.9 ; p<0.01$ ). The func- tional knee recovery was good, as expressed by the average score of the Lyshom Knee Scoring Scale (93.5) and the IKDC (74.7).

Conclusions: In the literature, a return to sport for international case studies and amateur sports is higher than our data. In our population we found the lack of information provided by the medical staff at discharge and follow-up. The assessment at a short-term follow up allowed us to verify that at the end of the post-surgical rehabilitation program the patients were uninformed about the timing and the ability to resume a sporting activity. An efficacious relationship between orthopedic doctor, physiotherapist and a doctor in motorial science may ensure proper treatment the patient after ACL reconstruction. It is important to guarantee the restarting of the sports activity to have a better quality of life in amateur sports.

Level of evidence: $v$.

KEY WORDS: return to sport, soccer, knee, surgery, anterior cruciate ligament.

\section{Introduction}

In the general population, Anterior Cruciate Ligament $(A C L)$ reconstruction is one of the most widely performed orthopaedic procedures, and it has a success rate of $97 \%^{1-3}$. The time to return to sport and the ability to continue sports activity are two important outcomes after anterior cruciate ligament (ACL) reconstruction. The return to sport is a confirmation of the full lower limb functional recovery. Also, it can be a good strategy for the full functional recovery and completion of rehabilitation.

Until now, the literature gives results about the return to sport after ACL reconstruction for sports population but results may be different between amateurs and professionals ${ }^{4}$. However, few studies regard patients who practice sport at an amateur level. Therefore, there are few data concerning patients involved in recreational activity and their rate of return to sports (RTS) and their performance upon RTS after an ACL tear ${ }^{5,6}$.

The data published in the literature are mainly from North America and Northern Europe ${ }^{7,8}$. It is interesting to investigate the strengths and weaknesses of current guidelines ${ }^{9,10}$. It is known that Italy has an important sports tradition in specific disciplines such as soccer ${ }^{11}$. But, on the other hand, it is lacking in sports promotion, starting from goodwill in the school con- 
text ${ }^{11}$. This background may affect proper reboot and return to sports practice after surgery. A retrospective analysis of what indications are given to amateur sportsmen and women after surgical treatment of the anterior cruciate ligament injury may allow the surgeon and physiatrist to analyze the completeness of the information provided and verify the opportunity of involving and expert in motorial and sports sciences to take charge of the patient.

We therefore conducted a retrospective study in which we analyzed all patient discharge letters following surgery for reconstruction of the anterior cruciate ligament to test both the specific information provided for the return to the sport and the actual return to sport.

\section{Material and methods}

We designed a retrospective study which included the analysis of all patients operated for ACL injury at the Unit of Orthopaedics and Traumatology of the Bari Hospital from January 2015 to September 2015. All of them underwent ACL reconstruction by one surgeon (B.M.). The research was conducted according to international standards ${ }^{12}$. Approval from the Local Committee Ethics was obtained.

All the patients satisfying the following inclusion criteria were enrolled in the study:

- acute trauma

- ACL lesion

- ACL reconstruction by a single surgeon (BM)

- pre-injury participation in amateur sports.

Exclusion criteria were:

- posterior cruciate ligament lesion

- medial collateral ligament lesion

- lateral collateral ligament lesion

- unstable contralateral knee

- meniscal or chondral lesions

- systemic or local infection

- lower limb malalignment requiring surgery.

\section{Surgical intervention}

All patients had clinical signs of ACL tear, and magnetic resonance images (MRIs) were used to confirm the clinical diagnosis prior to surgery. Furthermore, the patients were evaluated under anesthesia for knee instability. Before surgery, Lachman and a pivot shift test were performed under anaesthesia and all were positive. Arthroscopic surgery was performed under general anesthesia in all cases, with administration of prophylactic intravenous antibiotics at induction and for a further 24 hours. The patients were operated within 30 days after trauma. Arthroscopic single-bundle ACL reconstruction using autogenous semitendinosus and gracilis tendon grafts was performed using standard portals in all cases. We used Arthrex - All-Inside ${ }^{\circledR}$ ACL Reconstruction consisting in femur suspension and interference for the tibia. Anteromedial and anterolateral arthroscopic portals were made ${ }^{13}$.

\section{Physical therapy intervention}

All patients were referred to a post-operative physical therapy program immediately after surgery. The patient began to ambulate wearing a brace unlocked at $0-45^{\circ}$ for the first 15 days and then at $0-90^{\circ}$ for another 15 days. This was in accordance with current practice that generally includes post-surgical brace during the initial weeks of recovery to protect the quadriceps of the inhibited knee from experiencing sudden flexion under weight-bearing loads ${ }^{14}$. The rehabilitation therapy program provides early restoration of knee range of motion and quadriceps function, progressive strengthening, neuromuscular training, and return to sport. Clinic-based treatments targeted full knee extension, maximal knee flexion, and gait retraining in the early phase ${ }^{14}$. Closed kinetic chain quadriceps exercises were initiated after 3 weeks, and open kinetic chain exercises were initiated 4 weeks after surgery. Hip and core muscle exercises were added as part of the program as required ${ }^{14}$. Static cycling was used for flexibility and aerobic training from the third postoperative week. Neuromuscular training was introduced after 1 month ${ }^{15}$.

Data collection included:

- the analysis of the medical records and discharge letters for:

- anthropometric and epidemiological data of patients [gender, age, Body Mass Index (BMI), smoking], which could be possible risks for surgical failure factors ${ }^{16}$

- indication to return to sport or not; eventual indications/contraindications for specific sports;

- details of the examination, scheduled for all patients, in the sixth month for:

- VAS (11 points total) to measure pain. The patients were asked to indicate their perceived pain intensity along a 10 point/cm horizontal line $(10=\text { severe pain; } 0=\text { no pain })^{17}$

- Lysholm and International Knee Documenting Committee (IKDC) Subjective scores.

The Lysholm score ranges from 0 to 100 points and is based on eight items: limp, locking, pain, stairclimbing, support, instability, swelling, and squatting. A score of 95 to 100 is considered to be excellent, 84 to 94 is good, 65 to 83 is fair, and $<65$ is poor ${ }^{18}$. IKDC is a subjective scale that provides patients with an overall function score. The questionnaire looks at 3 categories: symptoms, sports activity and knee function $^{19}$.

- telephone interview of the patient at the average of $13(\mathrm{SD}+/-2)$ months after surgery to check:

- real return to sports activities and timing (expressed in months)

- the sports activity and recreational/competitive level (according to Tegner activity scores) preinjury and at the time of the interview.

The Tegner activity scale is a numerical scale ranging from an activity level of 0 (sick leave or disability pension due to knee problems) to 10 (competitive sports on a very high level). Recreational sports are those 
activities where the primary purpose of the activity is participation, with the related goals of improved physical fitness, fun, and social involvement often prominent. Competitive sports are centered on the achievement of success and the attainment of physical skills through rigorous training.

These tools are easy to administer, short in length, and have been validated as clinician and patient-administered instruments for a variety of knee conditions, primarily anterior cruciate ligament (ACL) and other ligament injuries, but also for chondral disorders, meniscal injuries, and patellar dislocation ${ }^{18,20,21}$.

\section{Statistical analysis}

The data concerning the medical records of each patient and the telephone interview were put into forms and a database was built up with File Maker Pro software. The data were analyzed with software STATA MP11 (StataCorp LP, College Station, Texas 77845 USA).

The continuous variables were described as means with the indication of the standard deviations and the Student t-test for paired samples was used for the comparison of averages. The categorical variables were expressed as proportions. The effects of the restart of sport and the anthropometric variables on the post-surgery outcomes were assessed by multiple logistic regression models (for categorical variables) and multiple linear regression (for continuous variables). For all the tests used it was considered significant a value of $p<0.05$.

\section{Results}

All patients who were within the inclusion criteria and that we selected for the study answered the phone. The study sample was composed of 80 subjects, of which $92.5 \%$ males (age: $29.7+/-8.4$ years old). In the sample there emerged a mean weight of $76.8 \pm 12$ $\mathrm{kg}$, an average height of $1.75 \pm 0.8$ meters and an average BMI of $25 \pm 3.1 \mathrm{~kg} 50 \%$ of subjects $(n=40)$ were smokers.

\section{Discharge letter/Follow Ups (F.Us)}

As for the indications to return to sports activity in the discharge letter or subsequent F.Us, only one patient was told he could restart the sports activity at the end of rehabilitation, without further indications/contraindications.

\section{Return to sports activities}

At the time of the interview, $47.5 \%$ had restarted sport; the logistic regression analysis showed that smoking habits $(\mathrm{OR}=0: 13 ; 95 \% \mathrm{Cl}=0.03-0.67 ; \mathrm{z}=$ $2.5 ; \mathrm{p}=0.014)$ and $\mathrm{BMI}(\mathrm{OR}=0.69 ; 95 \% \mathrm{Cl}=0.50-$
Table I. Sport activity before the trauma and follow up.

\begin{tabular}{lll}
\hline & Pre-surgery & Post-surgery \\
\hline Jogging & 2 & 0 \\
Cycling & 2 & 0 \\
Volleyball & 3 & 5 \\
Tennis & 3 & 5 \\
Basketball & 2 & 1 \\
Soccer & 54 & 14 \\
Running & 4 & 5 \\
Athetics & 10 & 8 \\
Total & 80 & 38 \\
\hline
\end{tabular}

$0.94 ; z=2.3 ; p=0.02$ ) could reduce the probability to return to the sports activities after surgery; among those who had restarted the sport, almost all (32) did the same sport practiced before the surgery. The average time to return to a sports activity was 8 months. The type of sports made before and after surgery are described in Table I. There was a significant reduction of the competitive level or physical commitment, comparing the pre-operative Tegner activity score with the post-operative one (respectively, 6.9 and 3.9; $\mathrm{p}<0.01$ ). Before the surgery, $75 \%$ performed a level 7 activity (competitive or recreational sport), while $12.5 \%$ a level 8 activity (competitive sport); $5 \%$ a level 5 activity (competitive sports recreational or at least twice weekly) and a $7.5 \%$ level 6 activity (recreational sports at least 5 times per week).

After surgery, $45 \%$ were at Level 1 (work sedentary activity), $27.5 \%$ performed a level 7 activity (competitive or recreational sport), $10 \%$ level 8 activity (competitive sport), $12.5 \%$ a level 6 activity (recreational sports at least 5 times per week), and $7.5 \%$ a level 2 activity (work-light labor).

The results showed that the surgery negatively impacted on the return to sports (agreement $=42.5 \%$; $\mathrm{K}$ $=0.25, z=4.9 ; p<0.0001)$. We did not find any differences in clinical scales between patients who returned to sport and patients who did not return to sport activities.

\section{Lysholm Knee Scoring Scale}

The average score of the Lyshom Knee Scoring Scale was good, as was the total score (93.5 +/-2.4/ 100).

In the linear model multivariate analysis, the restarting of the same sport performed before surgery determined an improvement of the total score value (coef $=16 ; 95 \% \mathrm{Cl}=3.5-28.3 ; \mathrm{t}=2.22 ; \mathrm{p}<0.0001)$.

\section{IKDC}

The average score was $74.7+/-16.9$. Patients report- 
ed that a mean number of episodes of pain in the last four weeks was $2.7 \pm 1.9$ and the mean VAS was 2.3 \pm 2 .0. The linear regression model showed that the restarting of the same sports after surgery improved the score $($ coef $=2.3 ; 95 \% \mathrm{Cl}=0.9-3.8 ; \mathrm{t}=3.3 ; \mathrm{p}=$ 0.002).

\section{Discussion}

In literature the rate of return to sport is higher in elite sports compared to our series: between $76 \%$ to $95 \%$ of professional soccer players reached the same activity level performed before injury after 12 months ${ }^{22-}$ 24 . After 7 years this percentage drops to $26 \% 25$. Erickson et al. showed that $97 \%$ of National Hockey League Players return to sport after anterior cruciate ligament reconstruction, at a mean of $7.8 \pm 2.4$ months following surgery ${ }^{26}$. However, these sportmen showed a significant decline in games played per season versus controls following ACL reconstruction. A recent meta-analysis, published by Ardern et al. ${ }^{7}$, presents the rates of return to the sport in the general population after ACL reconstruction surgery. 7000 participants were analyzed and 4 in every $5(80 \%)$ returned to some form of sport following surgery. On average, 2 in 3 participants returned to their preinjury level, and only $55 \%$ returned to competitive level sport.

As regards the surgical procedure, there are only minor differences in relation to the type of graft 27 . Patients treated with patellar tendon grafts had modestly increased odds of returning to their preinjury level sport compared with those with hamstring tendon grafts $^{28}$. On the other hand, people who received hamstring tendon grafts had more probability of returning ${ }^{28}$. Moreover, the literature shows an increased risk of ACL graft rupture for hamstring grafts $^{7}$. These differences, however, can be put down to the different techniques that surgeon may choose from, as well as the rehabilitation program in relation to whether the patient is or is not a professional athlete. It is important to mention that the elite athletes have greater access to exceptional medical care and physical rehabilitation than the average citizen.

In another series using the same surgery procedure as ours, $79.5 \%$ of the patients resumed to their preinjury level of sport at 6 months ${ }^{29}$. The results of our work show, notwithstanding functional recovery, a low return to sporting activity $(47.5 \%)$.

Our data showed that the patients who returned to sports, chose less competitive sports. These results are in agreement with the literature, which shows the type of sports affected the chances of successful return to sports. Patients who participated in sports that did not require jumping, hard pivoting, and cutting activities had a greater chance of successfully returning to preinjury sports $(87 \%)$ as compared with patients who participated $(61.4 \%)$ in jumping, hard pivoting, and cutting activities, although these results were not statistically significant. We also found a low percentage of patients returning to their pre-injury level of sport. The reasons for this regressive sporting level are mainly due to fear of movement and reinjury (or kinesiophobia) ${ }^{7}$ as frequently cited reasons in $20 \%$ to $24 \%$ of patients ${ }^{30}$. Other variables include impaired knee function ${ }^{31,32}$, instability ${ }^{30,33}$, pain ${ }^{33,34}$, social reasons $^{30}$, low self-motivation ${ }^{32}$, effusion ${ }^{33}$, muscle weakness ${ }^{31,33}$, and knee extension deficit ${ }^{34}$. Kinesiophobia and fear of re-injury could be more important in competitive athletes as a higher level of aggressiveness and neglect of safety during training as well as competition could be involved, predisposing to higher risk profiles for injury.

On the other hand, our data show that the return to the sport guaranteed a better functional recovery. However, we have to report the study by Ericsson et al. ${ }^{35}$ who reported that patients need to achieve a sufficient level of physical functioning to enable optimal performance of sport-specific tasks. Consequently, the practice of a sports activity represents an adequate physical and psychological motivation to ensure a subsequent return to the sport. The return to sport allows us to optimize the functional recovery. The researchers underlined the role of psychological factors in getting athletes back on the playing field.

Our population was made over whelmingly up of men. It should be noted however that the literature reports that the incidence of anterior cruciate ligament rupture in the sports population is more frequently for women ${ }^{36,37}$. On the basis of this data we could assume a low commitment to sport by women or less involvement in contact sports in our region. Male gender and younger age ${ }^{24}$ are factors associated with a return to sport after ACLR, while activity-related knee pain and cartilage injury are factors associated with not returning to sport.

A recent study found that all individuals undergoing ACLR expected to have normal or almost normal knee function within 1 year of ACLR, and $91 \%$ expected to return to their pre-injury level of sport ${ }^{38}$. Participants who had returned to their pre-injury sport or recreational activity had more positive responses to the psychological outcomes, a higher knee-related quality of life and self-reported knee function, were more satisfied with their current knee function, and reported better knee function in sport and recreational activities compared to those who had not returned to sports.

The major limitations of this study is its retrospective design and the short duration of the study. The sample size is small, although the other series reported a similar number of patients, and the follow-up may not have been long enough to detect further failures and inability to continue sport activity. Because of the defined inclusion criteria of time since surgery, only a limited number of patients was eligible to participate. We were unable to verify the exact time spent doing sports, full or limited participation, and training/match exposure. Lastly, the lack of instrument examinations prevented the detection of eventual surgical failures. Thus, we lack a control group to compare to the effectiveness of specific guidance provided at discharge. 
Despite the limitations inherent in the study design, the results suggest that we have to provide more guidance to all patients about their return to sport, even when they are not professional sportsmen or sportswomen. This study identified a lack of communication between surgeons and experts in the field of sports, such as a those with a degree in motorial sciences and/or sports, especially as regards the care of people involved in recreational sport. Future prospective studies are needed to verify whether precise medical can improve time and results of return to sport.

\section{Conclusions}

In conclusion, we found a low rate to return to sport. In the light of this result, it is important to improve the information giving to the patient. Also the orthopedic doctor or physical therapist should be more aware of the need for this information. In the presence of a good functional recovery at 6 months the patient could resume sport with a consequent better functional recovery of the operated knee.

\section{Conflicts of interest}

The Authors declare no conflicts of interest concerning this article.

\section{References}

1. Chang SK, Egami DK, Shaieb MD, Kan DM, Richardson AB. Anterior cruciate ligament reconstruction: allograft versus autograft. Arthroscopy. 2003;19(5):453-462.

2. Legnani C, Terzaghi C, Borgo E, Ventura A. Management of anterior cruciate ligament rupture in patients aged 40 years and older. J Orthop Traumatol. 2011;12(4):177-184.

3. Ardern CL, Taylor NF, Feller JA, Webster KE. Return-to-sport outcomes at 2 to 7 years after anterior cruciate ligament reconstruction surgery. Am J Sports Med. 2012;40(1):41-48.

4. Oztekin HH, Boya H, Ozcan O, Zeren B, Pinar P. Pain and affective distress before and after ACL surgery: a comparison of amateur and professional male soccer players in the early postoperative period. Knee. 2008;15(5):368-372.

5. Filbay SR, Crossley KM, Ackerman IN. Activity preferences, lifestyle modifications and re-injury fears influence longer-term quality of life in people with knee symptoms following anterior cruciate ligament reconstruction: a qualitative study. J Physiother. 2016;62(2):103-110.

6. Tjong VK, Murnaghan ML, Nyhof-Young JM, Ogilvie-Harris DJ. A qualitative investigation of the decision to return to sport after anterior cruciate ligament reconstruction: to play or not to play. Am J Sports Med. 2014;42(2):336-342.

7. Ardern CL, Webster KE, Taylor NF, Feller JA. Return to sport following anterior cruciate ligament reconstruction surgery: a systematic review and meta-analysis of the state of play. $\mathrm{Br} J$ Sports Med. 2011;45:596-606.

8. Lewis PB, Parameswaran AD, Rue JP, Bach BR Jr. Systematic review of single-bundle anterior cruciate ligament reconstruction outcomes: a baseline assessment for consideration of double-bundle techniques. Am J Sports Med. 2008;36(10): 2028-2036.
9. van Melick N, van Cingel RE, Brooijmans F, et al. Evidencebased clinical practice update: practice guidelines for anterior cruciate ligament rehabilitation based on a systematic review and multidisciplinary consensus. Br J Sports Med. 2016.

10. Myklebust G, Bahr R. Return to play guidelines after anterior cruciate ligament surgery. Br J Sports Med. 2005;39(3):127131.

11. Nauright J, Parrish C. Sports around the World. History, Culture, and Practice. ABC-CLIO, 2012.

12. Padulo J, Oliva F, Frizziero A, Maffulli N. Muscles, Ligaments and Tendons Journal - Basic principles and recommendations in clinical and field Science Research: 2016 Update. MLTJ. 2016;6(1):1-5.

13. Saka T. Principles of postoperative anterior cruciate ligament rehabilitation. World J Orthop. 2014;5(4):450-459.

14. Van Grinsven S, van Cingel RE, Holla CJ, Van Loon CJ. Evidence based rehabilitation following anterior cruciate ligament reconstruction. Knee Surg Sports Traumatol Arthrosc. 2010;1 8:1128-1144.

15. Myer GD, Paterno MV, Ford KR, Quatman CE, Hewett TE. Rehabilitation after anterior cruciate ligament reconstruction: criteria-based. The Orthopaedic Journal of Sports Medicine Supervised Rehabilitation Improves Chance of Return to Sport 7 progression through the return-to-sport phase. J Orthop Sports Phys Ther. 2006;36:385-402.

16. Novikov DA, Swensen SJ, Buza IJA, Gidumal RH, Strauss EJ. The Effect of Smoking on ACL Reconstruction: A Systematic Review. Phys Sportsmed. 2016.

17. Byrnes KR, Waynant RW, llev IK, et al. Light promotes regeneration and functional recovery and alters the immune response after spinal cord injury. Lasers Surg Med. 2005;36(3): 171-185.

18. Briggs KK, Lysholm J, Tegner Y, Rodkey WG, Kocher MS, Steadman JR. The Reliability, Validity, and Responsiveness of the Lysholm Score and Tegner Activity Scale for Anterior Cruciate Ligament Injuries of the Knee. Am J Sports Med. 2009; 37(5):890-897.

19. Hefti F, Muller W, Jakob RP, Staubli HU. Evaluation of knee ligament injuries with the IKDC form. Knee Surg Sports Traumatol Arthrosc. 1993;1-3-4:226-234.

20. Tegner Y, Lysholm J. Rating Systems in the Evaluation of Knee Ligament Injuries. Clin Orthop Relat Res. 1985;198:4349.

21. Lysholm J, Gillquist J. Evaluation of knee ligament surgery results with special emphasis on use of a scoring scale. Am J Sports Med. 1982;10(3):150-154.

22. Zaffagnini S, Grassi A, Marcheggiani Muccioli GM, Tsapralis K, Ricci M, Bragonzoni L, Della Villa S, Marcacci M. Return to sport after anterior cruciate ligament reconstruction in professional soccer players. Knee. 2014;21(3):731-735.

23. Walden M, Hagglund M, Magnusson H, Ekstrand J. Anterior cruciate ligament injury in elite football: a prospective three-cohort study. Knee Surg Sports Traumatol Arthrosc. 2011;19:11 19.

24. Brophy RH, Schmitz L, Wright RW, et al. Return to play and future $\mathrm{ACL}$ injury risk after $\mathrm{ACL}$ reconstruction in soccer athletes from the Multicenter Orthopaedic Outcomes Network (MOON) group. Am J Sports Med. 2012;40:2517-2522.

25. Roos H, Ornell M, Gardsell $P$, Lohmander LS, Lindstrand A. Soccer after anterior cruciate ligament injury-an incompatible combination? A national survey of incidence and risk factors and a 7-year follow-up of 310 players. Acta Orthop Scand. 1995;66:107-112.

26. Erickson BJ, Harris JD, Cole BJ, et al. Performance and Return to Sport After Anterior Cruciate Ligament Reconstruction in National Hockey League Players. Orthop J Sports Med. 2014;2(9):2325967114548831.

27. Mascarenhas R, Tranovich MJ, Kropf EJ, Fu FH, Harner CD. 
Bone-patellar tendon-bone autograft versus hamstring autograft anterior cruciate ligament reconstruction in the young athlete: a retrospective matched analysis with 2-10 year followup. Knee Surg Sports Traumatol Arthrosc. 2012;20(8):15201527.

28. Webster KE, Feller JA, Hartnett N, Leigh WB, Richmond AK. Comparison of Patellar Tendon and Hamstring Tendon Anterior Cruciate Ligament Reconstruction: A 15-Year Follow-up of a Randomized Controlled Trial. Am J Sports Med. 2016;44 (1):83-90.

29. Müller U, Krüger-Franke M, Schmidt M, Rosemeyer B. Predictive parameters for return to pre-injury level of sport 6 months following anterior cruciate ligament reconstruction surgery. Knee Surg Sports Traumatol Arthrosc. 2015;23(12):36233631.

30. Lee DY, Karim SA, Chang HC. Return to sports after anterior cruciate ligament reconstruction-a review of patients with minimum 5-year follow-up. Ann Acad Med Singapore. 2008;37: 273-278.

31. Czuppon S, Racette BA, Klein SE, Harris-Hayes M. Variables associated with return to sport following anterior cruciate ligament reconstruction: a systematic review. $\mathrm{Br} \mathrm{J}$ Sports Med. 2014;48:356-364.

32. Kvist J, Ek A, Sporrstedt K, Good L. Fear of re-injury: a hindrance for returning to sports after anterior cruciate ligament reconstruction. Knee Surg Sports Traumatol Arthrosc.
2005;13:393-397.

33. Lentz TA, Zeppieri G Jr, Tillman SM, et al. Return to preinjury sports participation following anterior cruciate ligament reconstruction: contributions of demographic, knee impairment, and self-report measures. J Orthop Sports Phys Ther. 2012;42: 893-901.

34. Gobbi A, Francisco R. Factors affecting return to sports after anterior cruciate ligament reconstruction with patellar tendon and hamstring graft: a prospective clinical investigation. Knee Surg Sports Traumatol Arthrosc. 2006;14:1021-1028.

35. Ericsson YB, Roos EM, Frobell RB. Lower extremity performance following ACL rehabilitation in the KANON-trial: impact of reconstruction and predictive value at 2 and 5 years. $\mathrm{Br} \mathrm{J}$ Sports Med. 2013;47:980-985.

36. Prodromos CC, Han Y, Rogowski J, Joyce B, Shi K. A metaanalysis of the incidence of anterior cruciate ligament tears as a function of gender, sport, and a knee injury-reduction regimen. Arthroscopy. 2007;23(12):1320-1325.

37. Filbay SR, Ackerman IN, Russell TG, Crossley KM. Return to sport matters-longer-term quality of life after $\mathrm{ACL}$ reconstruction in people with knee difficulties. Scand J Med Sci Sports. 2016.

38. Feucht MJ, Cotic M, Saier T, Minzlaff P, Plath JE, Imhoff AB, Hinterwimmer S. Patient expectations of primary and revision anterior cruciate ligament reconstruction. Knee Surg Sports Traumatol Arthrosc. 2014:24:201-217. 